\title{
Double-principal Agent: False Accounting Information, Supervision Cost and Corporate Performance
}

\author{
Wuqing WU \\ School of Business, Renmin University of China, Beijing 100872, China \\ E-mail: wuwuqing@rbs.org.cn \\ Suning AN \\ School of Business, Renmin University of China, Beijing 100872, China \\ E-mail: ibendou@126.com
}

\begin{abstract}
The game among the corporate controlling shareholder, the shareholder in power balance and the manager can lead to severe agency problems. This paper regards the shareholder in power balance as another principal and applies the latest results about double-principal agent theory in the research of manager tunneling, supervision cost and corporate performance, trying to solve the inconsistency of the above corporate governance issue researched by domestic and foreign scholars. The main conclusions are as the followings. The correlation among them depends on which one has a dominant position, the free rider effect of supervision or the positive externality effect on cash flow right. Therefore, the key to excite the positive effect of the corporate governance mechanism such as the check-and-balance of stock ownership is the degree of cooperation between shareholders.
\end{abstract}

Keywords corporate finance; check-and-balance of stock ownership; double-principal agent theory; corporate performance

\section{Introduction}

The emergence of joint stock companies, especially the separation of ownership and control in joint stock companies ${ }^{[1]}$, symbolizes the establishment of modern enterprise system. The ownership structure has changed fundamentally with managers becoming actual controllers of enterprises, which makes it necessary to monitor managers. Since then, the principal-agent problem between shareholder and manager has become popular. An early systematic research on the interest conflict between internal manager and external shareholder is Jensen and Meckling's ${ }^{[2]}$ work based on the standard principal-agent theory. Shareholders have corporate cash flow right in proportion with the shares they hold, whereas managers obtain performance-based compensation. Managers' target function differs from shareholders', leading to the expropriation of shareholders' interest. Both convergence of interest and enhancement of supervision are important measures to reduce agency cost ${ }^{[2]}$.

The concept of private benefits of control ${ }^{[3]}$ raises a new principal-agent problem to entrepreneurs and scholars. Porta et al. ${ }^{[4]}$ claims that in countries except the US enterprises'

Received December 13, 2013, accepted December 26, 2013

Supported by the Fundamental Research Funds for the Central Universities, the Research Funds of Renmin University of China (11XNK027) 
core agency problem is how to prevent controlling shareholders from expropriating minority shareholders rather than the principal-agent problem between managers and shareholders. Controlling shareholders pursue their own interest at the cost of minority shareholders' interest, resulting in the agency problem between the two types of shareholders ${ }^{[4-6]}$.

The existence of shareholders in power balance and the co-existence of multiple major shareholders are possible ways to solve such agency problem. However, the double- or multipleprincipal agent problem is likely to occur between multiple shareholders and a manager. A number of issues related to the new problems are worth studying: what new phenomena associate with agents will happen in the double-principal context? How can we make the controlling shareholders mechanism more effective? How can the corporate performance be improved in the double-principal agent governance environment? This paper focuses on an interesting issue of finding an effective way to prevent managers from providing false performance through financial reporting and to operate the performance-based motivation mechanism designed by investors in the double-principal agent ownership structure.

Since Jensen and Meckling ${ }^{[2]}$ bring forward the concept of agency cost, the relationship between ownership structure and corporate performance has drawn much attention in corporate governance. One point of view is that check-and-balance of stock ownership is more effective in corporate governance than is "absolute ratio share" ${ }^{1}$. Major stockholders with willingness in and ability to check-and-balance constrain ${ }^{[7]}$ and monitor ${ }^{[8]}$ controlling stockholders' rights through balancing power, and it also effectively reduces agency cost ${ }^{[9]}$. Their goals are consistent with other major stockholders, which makes it more effective to protect investors and to improve corporate performance. Domestic scholars Sun et al.. ${ }^{[10]}$, Chen et al..11], Bai et al. ${ }^{[12]}$, Liu et al. ${ }^{[13]}$ support this point of view. Recent studies of Tu et al. ${ }^{[14]}$, Tong et al. ${ }^{[15]}$, Peng ${ }^{[7]}$ also provide evidence to some extent. Maury and Pajuste ${ }^{[16]}$ argue that check-and-balance of stock ownership and stockholders collusion are associated with corporate governance in two opposite directions. Action of collusion can obtain joint private benefits ${ }^{[13,15]}$ while check-and-balance possibly have no influence on controlling stockholders' tunneling behavior ${ }^{[17]}$. The third point of view is that ownership balance does not necessarily have the check-and-balance effect ${ }^{[14]}$. Even if such effect exists, it is limited and constrained mainly to self-interest behaviors such as related party transactions among controlling shareholders and misappropriation type of related party transactions, and it cannot prevent listed companies' cash dividends behaviors ${ }^{[18]}$ and even leads to corporate control problem ${ }^{[19-21]}$ hence worse corporate performance. Recent studies have made various progress in check-and-balance patterns ${ }^{[22]}$, the property of shareholders in power balance ${ }^{[14,23]}$, firm growth characteristics ${ }^{[15,24]}$ and company performance volatility ${ }^{[25]}$, but empirical results are still mixed.

Theoretical discussion in double-principal agent mechanism can partially solve the problem of inconsistency among domestic and foreign scholars, thus it is of significant theoretical value. The emergence of shareholder in power balance symbolizes crucial changes in corporate governance environment. As another principal, shareholder in power balance has not only cooperative and restrictive effect on controlling shareholder, but also motivating and monitoring function

\footnotetext{
${ }^{1} \mathrm{Li} \mathrm{Y}$. Check-and-balance of stock ownership benefits the improvement of corporate governance structure. China Securities Journal, June 22, 2001.
} 
on managers. Due to the endogenous problem in the corporate ownership structure ${ }^{[22,26,27]}$, this paper argues that the relationship between ownership structure and corporate performance would be clearer in the context of double-principal agent, which has been rarely studied so far. This paper's discussion in the perspective of double-principal agent makes contribution threefold: firstly, it raises the awareness of the emerging check-and-balance of stock ownership as a symbol of the emerging double-principal agent problem, a new type of principal-agent problem; secondly, it helps demonstrate theoretically the endogenous attribute of ownership structure; thirdly, it provides an theoretical explanation to the inconsistency in current empirical results.

Multiple-principal agent problem is not uncommon in multilateral games but comes with few theoretical results and limited application ${ }^{[28-29]}$. This paper applies Khalil, Martimort and Parigi's ${ }^{[31]}$ analysis framework of multiple-principal agent problem about financial contracting to study the relationship between false accounting information, supervision cost and corporate performance. In this paper, the double-principal agent problem consists of two principals, the controlling shareholder and the shareholder in power balance, and an agent, the manager. The manager has private information on her own type, on whether accounting information is true or false and on the degree of falseness. This paper assumes that the controlling shareholder and the shareholder in power balance have incomplete information on the manager's type but could motivate and constrain the manager through equity-based incentives, performance-based bonus and punishment policy, although improving supervision generates certain amount of cost.

The main conclusions are as the followings. When the controlling shareholder cooperates completely with the shareholder in power balance in sharing return on equity and management supervision, their utility is maximized relatively. When they only cooperate in management supervision, the positive externality effect would lead to excessive monitoring. And when they do not cooperative at all, the free-rider effect on supervision dominates the outcome of the game.

\section{Double-principal game model}

\subsection{Assumptions}

It is worth studying how information sharing and decision-making cooperation between principals affect the outcome of the game in multiple-principal agent problem. Thus, this paper studies how cooperation on cash flow right and management supervision right between the controlling shareholder and the shareholder in power balance affect each party's decisionmaking and the game's equilibrium. Our research focuses on three conditions related to different degrees of cooperation, that is, complete cooperation (cooperation on both cash flow right and management supervision), supervision cooperation (cooperation on management supervision only) and complete non-cooperation. Intuitively, the condition of complete cooperation between multiple principals is similar to the single principal problem, while other two conditions lead to new games due to free-rider effect or supervision spill-over effect. This principal-agent is not uncommon: the corporate shareholders obtain return on equity according to reported profits prepared by the manager; when the manager is suspected of providing false accounting reports and giving false information on corporate performance, the shareholders fulfill the right of accounting information verification such as auditing by third-party CPAs to verify the fairness 
of accounting information ${ }^{[30]}$, then decide whether to impose a penalty on the manager and share supervision benefit; however, supervision generates certain amount ${ }^{2}$ of cost. Based on these analyses, the assumptions are as the followings.

Assumption 1 Corporate shareholders' cash flow right is reduced to the acquirement of return on equity. Management supervision right is reduced to supervision on the manager, which is particularly referred to verification on the manager's accounting information.

Assumption 2 The managers is opportunistic.

Assumption 3 Shareholders have full capability of recognizing false accounting information provided by the manager.

Assumption 4 Supervision benefit is divided equally by the controlling shareholder and the shareholder in power balance.

Assumption 5 Supervision cost exists but it is less than supervision benefit.

\subsection{Game process design}

Game process Firstly, the controlling shareholder $H_{1}$ and the shareholder in power balance $H_{2}$ announce a mechanism of cash flow right and a management supervision scheme they choose, that is, they announce the return on equity function, accounting information verification probability and verification cost function, etc.; secondly, the manager has a trade-off between advantages and disadvantages in accordance with her own type $\theta$ which belongs to a certain type space $\Theta$, then she discloses accounting information and pays $\hat{\theta}$; finally, shareholders decide whether to audit according to the accounting verification probability $p_{1}(\hat{\theta})$ and $p_{2}(\hat{\theta})$.

Manager's type parameter $\theta$ It is defined as supervision benefit ${ }^{3}$ transferred to shareholders or its increasing function. $\theta$ stands for the manager's private information and its random distribution form is common knowledge. $\theta$ has a continuous distribution $F(\theta)$ on the interval $[\underline{\theta}, \bar{\theta}]$ where the lowest bound is $\underline{\theta}>0$ and the highest bound is $\bar{\theta}<\infty$, and its destiny function is $f(\theta)>0$ for all $\theta$. For technical reasons, assume a weakly decreasing hazard rate $\frac{1-F(\theta)}{f(\theta)}$. The controlling shareholder and the shareholder in power balance do not know actual value of $\theta$, but they can look into the value through supervision measures such as accounting verification at some cost. In the condition of complete information, that is, when shareholders know the manager's actual $\theta$, they can obtain complete benefit $\bar{\theta}$. However, if there exists information asymmetry and no supervision measures are taken, shareholders' supervision benefit is $\underline{\theta}$.

Verification cost Accounting verification comes at certain cost, for instance, audit fees paid to CPAs who are specialized in verification business. Denote verification cost for $H_{k}$ by $C\left(p_{k}\right)$. The cost function satisfies:

1) $C(0)=0$;

2) Inada conditions $C^{\prime}(0)=0, C^{\prime}(1)=\infty$;

3) $C^{\prime}\left(p_{k}\right)>0$ for $p_{k} \in(0,1)$;

4) $C^{\prime \prime}\left(p_{k}\right)>0$ for all $p_{k}$.

\footnotetext{
${ }^{2}$ Due to controlling shareholder's tunneling behavior, the actual return of equity gained by shareholders is not obtained necessarily according to share proportion.

${ }^{3}$ Supervision benefit includes extra private benefits of control or the value that the manager creates for corporation by her normal effort. Due to information asymmetry and imperfect contract, the manager is likely to reduce effort or prepare false accounting reports to give false performance information.
} 
$H_{1}$ and $H_{2}$ 's choices are to choose proper return on equity functions $R_{1}(\cdot)$ and $R_{2}(\cdot)$ in the decision of cash follow right and to choose proper accounting information verification probabilities $p_{1}(\theta)$ and $p_{2}(\theta)$ in the decision of management supervision in order to maximize individual utility function. We can assume that $R_{k}(\cdot)$ is a function of verification probability because return on equity depends on reported profits and the manager decides the falseness degree of accounting information according to shareholders' supervision level.

After the manager discloses accounting information, two principals verify the reported accounting information according to their verification probability $p_{k}{ }^{4}$, review the reported accounting information, check the transferred profits and impose a penalty. Assume that $p_{k}$ is common knowledge as long as accounting verification probability is given. Denote $1-q=$ $\left(1-p_{1}\right)\left(1-p_{2}\right)$, then $q$ stands for the controlling shareholder and the shareholder in power balance's joint verification probability.

Simply assume that yield from accounting information verification is $q \theta$ and it is divided equally between the two principals according to Assumption 4. $q$ connects two principals' verification probability and sets yield share. Because $q$ is an increasing function of $p_{k}$, an increase in accounting verification by one principal would benefit another principal. However, because the second-order cross partial derivative of $q$ is less than zero, the marginal benefit associated with an increase in accounting verification by one principal is decreasing. In this case, another principal would raise her verification probability in order to gain a matching benefit. Then it is likely to become wasteful in management supervision cost.

\subsection{The Khalil-Martimort-Parigi model}

Assume that shareholders and agent are risk neutral. The agent's utility function is $U=$ $(1-q) \theta-R_{1}-R_{2}$ with a budget constraint $U \geq 0$. Therefore, the agent's decision is a trade-off between information rent $(\theta)$, return on equity payment $\left(R_{1}, R_{2}\right)$ and verification yield $(q \theta)$. The utility function of $H_{k}$ is $W_{k}=R_{k}+\frac{q \theta}{2}-C\left(p_{k}\right)$ where $W_{k} \geq 0$ according to Assumption 5 .

Khalil et al. ${ }^{[31]}$ provide an equilibrium solution theorem for their model. Regarding it as a theoretical foundation, the following part of this paper discusses how different degrees of cooperation affect principals' decision-making and behaviors in the game.

In the following parts of this paper, the superscript "*" indicates an equilibrium function. And the superscripts $m, c$ and $d$ respectively stand for the condition of complete cooperation, supervision cooperation and non-cooperation in cash flow right and management supervision between the controlling shareholder and the shareholder in power balance.

\section{Complete cooperation between the controlling shareholder and the shareholder in power balance}

\subsection{Shareholders' choice}

The complete cooperation between the controlling shareholder and the shareholder in power balance on cash flow right and management supervision incorporate that they share a joint transfer payment $R(\cdot)$ and decide $p_{1}$ and $p_{2}$ together, which results in a minimum cost (denoted

\footnotetext{
${ }^{4}$ For simplicity, assume manager's type could be identified by accounting verification.
} 
by $\tilde{C}(q))$ of joint accounting verification probability $q$, i.e.:

$$
\begin{gathered}
\tilde{C}(q)=\min _{p_{1}, p_{2}} C\left(p_{1}\right)+C\left(p_{2}\right) \\
\text { s.t. }: q=p_{1}+p_{2}-p_{1} p_{2}
\end{gathered}
$$

This optimization problem yields a unique solution when the condition $C^{\prime \prime}\left(p_{k}\right)>\frac{C^{\prime}\left(p_{k}\right)}{1-p_{k}}$ is satisfied $^{[31]}$.

\subsection{Manager's choice}

Because transfer payment $R(\cdot)$ is a function of $q$, the manager's utility function can be denoted by:

$$
\begin{array}{ll}
U(\theta)= & \max _{q}((1-q) \theta-R(q)) \\
\text { s.t. : } & U(\theta) \geq 0 \text { for all } \theta \\
& \dot{U}(\theta)=1-q(\theta)^{5} \\
& \dot{q}(\theta) \leq 0^{6}
\end{array}
$$

Incentive constraints In reality, an increase in verification probability $q(\cdot)$ leads to a decrease in the manager's information rent, which is what condition (3) stands for. And in order to discourage the agent from understating income, $q(\cdot)$ must be decreasing in $\theta$, which satisfies condition (4). The condition (4) also results in principals' decreasing marginal utility, and it means the total transfer payment from agent to principals is a concave function in $\theta$.

\subsection{Shareholders' utility}

Shareholders' principal-agent problem is to choose $R(\cdot)$ and $q(\cdot)$ in order to maximize their net payoff anticipating the agent's incentives:

$$
\begin{gathered}
\max _{\{q(\cdot), R(\cdot)\}} \int_{\underline{\theta}}^{\bar{\theta}} f(\theta)(-\tilde{C}(q(\theta))+\theta q(\theta)+R(q(\theta))) \mathrm{d} \theta \\
\text { s.t. : }(1)(2)(3)(4)
\end{gathered}
$$

Shareholders' trade-off Shareholders' decision is constrained by incentives, with a trade-off between $R(\cdot)$ and $q(\cdot)$. Actually, due to the fact that $q$ is a decreasing function of $\theta$ and $R(\cdot)$ is an increasing function of $\theta$ or due to the first-order condition of (1), i.e. $C \theta=R^{\prime}(q(\theta))$, we can prove that $R(\cdot)$ is a decreasing function of $q$. Specifically, for all $\theta>x$, an increase of $q(x)$ units in principals' marginal payoff equals to a decrease of $1-F(x)$ units in agent's information rent, costing an increase of $f(x) \tilde{C}^{\prime}(q(x))$ units in marginal cost.

A cut-off rule If the marginal verification cost were constant $(c), q(\theta)=0$ if and only if $c>\frac{1-F(\theta)}{f(\theta)} ; q(\theta)=1$ if and only if $c \leq \frac{1-F(\theta)}{f(\theta)}$. In this case, shareholders' verification decision is reduced to a simple comparison between the manager's statement $\hat{\theta}$ and a threshold value where no accounting verification occurs if $\hat{\theta}$ exceeds the threshold and accounting verification must occur if $\hat{\theta}$ is lower than the threshold. Such criterion is similar to the cut-off rule in single-principal model.

\footnotetext{
${ }^{5}$ The result is obtained using the envelope theorem.

${ }^{6}$ The result is obtained using the equilibrium solution theorem.
} 


\section{Cooperation in supervision between the controlling shareholder and the shareholder in power balance}

\subsection{Shareholders' choice}

Shareholders only cooperate in management supervision, therefore we can still assume that the controlling shareholder and the shareholder in power balance bear a joint accounting verification $\operatorname{cost} \tilde{C}(q)$ and share the yield from accounting information verification $q \theta$. In this case, $R_{k}(\cdot)$ is a function of $q$. Apparently, due to non-cooperation in cash flow right, principals deem the manager as an intermediary, send decision-making signals to each other and improve their own utility. As will be clearer later, due to the positive externality in the process of cash flow right, supervision cost is bigger than that in the condition of complete cooperation. Therefore, contact between principal and agent should be constrained.

The discussion can be made in the vicinity of equilibrium solution, hence we might as well assume that the controlling shareholder $H_{1}$ has already observed the shareholder in power balance's optimal cash flow function $R_{2}^{* c}(q)$, then we see how the controlling shareholder would choose $R_{1}(\cdot)$.

\subsection{Manager's choice}

The manager's utility function is as the following:

$$
U(\theta)=\max _{q}\left((1-q) \theta-R_{1}(q)-R_{2}^{* c}(q)\right) \text { for all } \theta
$$

With $R_{2}^{* c}(q)$ given, this utility function resembles (1), and constraints similar to $(2)(3)(4)$ exist where (3) can be obtained using the envelope theorem. In this case, the first-order condition of $q$ associated with (5) becomes:

$$
\theta+R_{1}^{\prime}(q(\theta))+R_{2}^{* c^{\prime}}(q(\theta))=0 \text { for all } \theta
$$

The positive externality (6) demonstrates that on one hand an increase in $q$ leads to a decrease in the marginal yield of $H_{1}$ when $\theta$ is constant. It can be proved that $R_{2}^{* c}(q)$ is a decreasing and convex function ${ }^{[31]}$, which is different from the complete cooperation condition. On the other hand, an increase in $q$ results in a partial marginal yield transfer from $H_{2}$ to $H_{1}$ by the agent. In other words, shareholders increase verification probability and gain positive externality benefits from the shareholder in power balance's cash flow, so they have incentive to improve supervision.

\subsection{Equilibrium analysis}

The controlling shareholder's behavior pattern can be analyzed intuitively. Because verification probability $q^{* c}(\theta)$ is a decreasing function of $\theta$, the manager knows that a higher verification probability is associated with a lower transferred supervision payoff to shareholders, which the shareholder in power balance $\left(H_{2}\right)$ knows; $H_{2}$ also knows that a higher verification probability is related to truthful statement by the manager; the controlling shareholder knows that $H_{2}$ knows, therefore he tries to mislead $H_{2}$ by claiming a higher verification probability and makes $H_{2}$ believe in a lower transfer yield from the manager, leading to a lower transfer payment from $H_{2}$ and an extra positive externality benefit for himself. 
Excessive monitoring The behavior pattern described above is also the one for the shareholder in power balance. Consequently, the equilibrium outcome of the game is an increased verification probability resulting from the positive externality effect dependable on another shareholder's cash flow right scheme adjustment, which is different from the complete cooperation condition. Considering principals and agent's total welfare and when the manager's payoff is exogenous, the lower accounting verification cost is, the higher total welfare is. Therefore, cooperation in supervision only between shareholders results in relatively excessive monitoring and a higher supervision cost.

To sum up, when the shareholders only cooperate in supervision, one shareholder tries to use the manager as an intermediary, sends signals and obtains partly another shareholder's yield. The specific method is that the shareholders propose to increase the joint accounting verification probability. On one hand, this method increases shareholders' own verification cost. On the other hand, this method brings positive externality benefit, which is a dominant factor for shareholders' total benefit. As a result, compared to the condition of complete cooperation, the joint accounting verification probability is higher in equilibrium, which means shareholders' larger tendency to supervision and leads to excessive monitoring. Using the equilibrium solution theorem we find that the equilibrium of the manager's utility in this condition is lower than that in the complete cooperation condition, that is, $U^{* c}(\theta)<U^{* m}(\theta)$; we also find that shareholders and manager's total welfare is lower while shareholders' welfare is higher.

\section{Non-cooperation between the controlling shareholder and the share- holder in power balance}

\subsection{Shareholders' choice}

Under this condition, the controlling shareholder and the shareholder in power balance cooperate in neither cash flow right nor management supervision. Hence it is acceptable to define that the controlling shareholder and the shareholder in power balance provide their own cash flow function $R_{k}(\cdot)$ and accounting verification probability $p_{k}$ independently where $R_{k}(\cdot)$ is a function of $p_{k}$, and that they bear their own accounting verification $\operatorname{cost} C\left(p_{k}\right)$ independently.

The discussion can be made in the vicinity of equilibrium solution, hence we might as well assume that the controlling shareholder has already observed the shareholder in power

balance's optimal cash flow function $R_{2}^{* d}\left(p_{2}\right)$ and then we see how the controlling shareholder would choose $R_{1}(\cdot)$.

\subsection{Manager's choice}

Define the agent's earning function before deducting the payment of controlling shareholder $H_{1}$ as the following:

$$
v\left(p_{1}, \theta\right)=\max _{p_{2}}\left(\left(1-p_{2}\right)\left(1-p_{1}\right) \theta-R_{2}^{* d}\left(p_{2}\right)\right)
$$

This facilitates our discussion: treating $v\left(p_{1}, \theta\right)$ as the manager's initial earning, we can consider the problem of controlling shareholder $H_{1}$ as a "one principal-one agent" problem. Denote $p_{2}$ in equilibrium by $p_{2}^{*}\left(p_{1}, \theta\right)$.

The first-order condition of (7) with respect to $p_{2}$ satisfies:

$$
\theta\left(1-p_{1}\right)=-R_{2}^{* d^{\prime}}\left(p_{2}^{*}\left(p_{1}, \theta\right)\right)
$$


Furthermore,

$$
\frac{\partial p_{2}^{*}}{\partial p_{1}}=\frac{\theta}{R_{2}^{* d^{\prime \prime}}\left(p_{2}^{*}\left(p_{1}, \theta\right)\right)} \text { and } \frac{\theta}{R_{2}^{* d^{\prime \prime}}\left(p_{2}^{*}\left(p_{1}, \theta\right)\right)}=-\frac{\theta \dot{p}_{2}^{*}}{1-p_{1}-\theta \dot{p}_{1}}
$$

In the symmetric equilibrium, there exists $p_{1}^{* d}=p_{2}^{* d}=p_{2}^{*}$ and $p_{2}^{*}$ is a non-increasing function of $\theta$ according to the equilibrium solution theorem, therefore $R_{2}^{d}(\cdot)$ is a convex function; and $0<\frac{\partial p_{2}^{*}}{\partial p_{1}}<1$.

The free-rider problem Because $\frac{\partial^{2} q}{\partial p_{1} \partial p_{2}}$, management supervision effects from the controlling shareholder and the shareholder in power balance are complementary, but such complementarity is incomplete due to $0<\frac{\partial p_{2}^{*}}{\partial p_{1}}<1$. Different from the condition of supervision cooperation where $\frac{\partial p_{2}^{*}}{\partial p_{1}}=1$ and the complementarity is complete, incomplete complementarity leads to a free-rider phenomenon in supervision: when one shareholder increases one unit of accounting verification $p_{k}$, the other principal increases less than one unit of accounting verification $p_{j}$. Furthermore, we can prove that $\frac{\partial p_{2}^{*}}{\partial p_{1}}<1$ also undermines the positive externality benefit from cash flow right. Ultimately, management supervision is inadequate and even no management supervision occurs when the manager's transfer payment is high.

The agent's utility function is as the following:

$$
U(\theta)=\max _{p_{1}}\left(v\left(p_{1}, \theta\right)-R_{1}\left(p_{1}\right)\right) \text { for all } \theta
$$

Constraints similar to (2)(3)(4) exist: (4) still holds according to the equilibrium solution theorem, with a marginal probability rather than a joint probability; the following similar to (3) can be obtained using the envelope theorem:

$$
\dot{U}(\theta)=v_{\theta}\left(p_{1}(\theta), \theta\right)-\left(1-p_{1}(\theta)\right)\left(1-p_{2}^{*}\left(p_{1}(\theta), \theta\right)\right),
$$

In this case, it depends on $p_{2}^{*}\left(p_{1}(\theta), \theta\right)$ then on $R_{2}^{d}(\cdot)$ indirectly.

\subsection{Equilibrium analysis}

Using the first-order condition of the utility function of the controlling shareholder $H_{1}$, we obtain the following:

$$
C^{\prime}\left(p_{1}^{* d}\right) \geq\left[\left(1-p_{2}^{*}\right)+\frac{\partial p_{2}^{*}}{\partial p_{1}}\left(1-p_{1}^{* d}\right)\right]\left(\frac{1-F(\theta)}{f(\theta)}-\frac{\theta}{2}\right)-\frac{\partial p_{2}^{*}}{\partial p_{1}} R_{2}^{* d^{\prime}}\left(p_{2}^{*}\right)^{7}
$$

Closely look into (11). (1) The terms in the square brackets on the right side of (11) consist of the total effect on the increase in joint verification probability $q$ resulting from an increase in the controlling shareholder's verification probability $p_{1}$. The total effect includes a direct effect $\left(1-p_{2}^{*}\right)$ and an indirect effect via $p_{2}^{*}$, i.e. $\frac{\partial p_{2}^{*}}{\partial p_{1}}\left(1-p_{1}^{* d}\right)$, which is undermined by the free-rider effect considering $0<\frac{\partial p_{2}^{*}}{\partial p_{1}}<1$. (2) The direct outcome of an increase in $q$ is a decrease by $\frac{1-F(\theta)}{f(\theta)}$ in agent's rent. $\frac{\theta}{2}$ of the decrease are transferred to the shareholder in power balance $H_{2}$. (3) $-\frac{\partial p_{2}^{*}}{\partial p_{1}} R_{2}^{*} d^{\prime}\left(p_{2}^{*}\right)$ is the positive externality benefit of $H_{1}$ gained from $H_{2}$. Compared to the condition of supervision cooperation, the positive externality benefit is lower due to $\frac{\partial p_{2}^{*}}{\partial p_{1}}<1$.

Equilibrium analysis In the state of equilibrium holds $p_{1}^{* d}=p_{2}^{*}$. Then we rewrite (11) using (9):

\footnotetext{
${ }^{7}$ The greater than or equal to symbol in this formula means that accounting verification probability can equal to zero.
} 


$$
C^{\prime}\left(p_{1}^{* d}\right) \geq\left(1-p_{1}^{* d}\right)\left(\frac{1-F}{f}\left(1+\frac{\partial p_{2}^{*}}{\partial p_{1}}\right)-\frac{\theta}{2}\left(1-\frac{\partial p_{2}^{*}}{\partial p_{1}}\right)\right)
$$

Firstly, we discuss the case of no monitoring when the manager's transfer payment is relatively high. In the analysis of (12), shareholders' marginal benefit from accounting verification is negative when the manager's transfer payment $\theta$ exceeds a certain level. Therefore, the shareholder in power balance's verification probability is insensitive to the controlling shareholder's, that is, $\frac{\partial p_{2}^{*}}{\partial p_{1}}$ is relatively small. In this case, the value of the right side of (12) is relatively small, and no monitoring occurs when it is smaller than that of the left side, that is to say, when marginal benefit is small than marginal supervision cost.

Secondly, we discuss the case of excessive monitoring when the manager's transfer payment is relatively low. When $\frac{\partial p_{2}^{*}}{\partial p_{1}}$ approaches 1 , the case is similar to the condition of supervision cooperation and the value of the right side of (12) is relatively large. When it is larger than that of the left side, excessive monitoring occurs.

To sum up, consistent with what is described in the equilibrium solution theorem, either no monitoring or excessive monitoring comes up in the condition of non-cooperation. And which phenomenon occurs depends on which effect plays a dominant role, the positive externality effect or the free-rider effect. When the manager is honest and the transfer payment is high, the case is similar to the complete cooperation condition and there exists a cut-off rule that no monitoring occurs when a threshold is beaten. When the manager's transfer payment is low, the case is similar to the condition of supervision cooperation and it leads to excessive monitoring. In addition, the minimization of verification cost results in the maximization of shareholders and manager's total welfare. In this aspect, no monitoring is better than monitoring and less monitoring is better than more monitoring. It is obvious, however, that the manager will take advantage of tunneling shareholders' interest.

\section{Conclusions}

After the separation of ownership and control, management supervision becomes an important issue in corporate governance. Studies of micro foundation based on principal-agent theory mainly focus on the relationship between a single principal and a manager. Compared to a large number of empirical studies on the relationship between manager's tunneling, supervision cost and corporate performance, theoretical studies on the inherent mechanism are rare. Therefore, the lack of studies on corresponding micro foundation leads to the lack of credibility of the correlation shown in empirical studies. And results in empirical studies are mixed without the establishment of theoretical framework. In addition, as far as we know, studies in the perspective of double-principal agent have not emerged in the current local and foreign literature yet. This paper fills the gaps mentioned above.

By establishing a double-principal agent game model between the controlling shareholder, the shareholder in power balance and the manager, this paper discusses how different degrees of cooperation between shareholders affect supervision cost and corporate performance. The main conclusion is that the change in major stockholders' utility mostly depends on which effect plays a dominant role, the free-rider effect in supervision or the positive externality effect in cash flow right. When stockholders only cooperate in supervision, the positive externality effect in cash 
flow right leads to excessive monitoring. When non-cooperation occurs, which effect dominates depends on the manager's degree of transfer payment: when the transfer payment is low, the positive externality effect leads to excessive monitoring; when the transfer payment is high, the free-rider effect dominates and leads to either inadequate monitoring or no monitoring. This paper extends Pagano and Roall's ${ }^{[33]}$ conclusions and provides further theoretical evidence.

This paper assumes that supervision yield is divided equally between the controlling shareholder and the shareholder in power balance and that the two shareholders have the same supervision cost function. In reality, however, the controlling shareholder and the shareholder in power balance's accounting verification benefit and cost are not symmetric, nor is their yield. For instance, it is possible that the controlling shareholder tunnels the interest of the shareholder in power balance and other minority shareholders. In addition, it is worth studying how different degrees of supervision intensity affect cash flow right and supervision payment. Therefore, this paper's extended model will focus on how the asymmetric behaviors of the controlling shareholder and the shareholder in power balances cash flow right and management supervision affect the equilibrium solution.

Acknowledgements We thank the referees for their time and comments.

\section{References}

[1] Berle A, Means G. The modern corporation and private property. New York: MacMillan, 1932.

[2] Jensen M C, Meckling W. Theory of the firm: Managerial behavior, agency cost and ownership structure. Journal of Financial Economics, 1976(3): 305-360.

[3] Grossman SHart O. Takeover bids, the free-rider problem, and the theory of the corporation. The Bell Journal of Economics, 1980, 11(1): 42-64.

[4] Porta R L, Lopez-De-Silanes F, Shleifer A. Corporate ownership around the world. Journal of Finance, 1999, 54(2): 471-517.

[5] Shleifer A, Vishny R. A survey of corporate governance. Journal of Finance, 1997, 52(2): 737-783.

[6] Porta R L, Lopez-de-Silanes F, Shleifer A, et al. Law and finance. Journal of Political Economy, 1998, 106: 1113-1155.

[7] Peng D. Largest shareholder control, institutional investor governance and corporate performance: Evidence based on the empirical research of the SZSE listed companies. Macroeconomics, 2011, 7: 50-55.

[8] Pagano M, Roell A. The choice of stock ownership structure: Agency costs, monitoring, and the decision to go public. Quarterly Journal of Economics, 1998, 113(1): 187-226.

[9] Lv J S, Deng H. Effect of ownership governance structure of listed company on the agent cost on the condition of full-circulation: Based on the empirical data of manufacture listed company from the SMEs board. China Soft Science Magazine, 2010, 11: 136-143.

[10] Sun Y X, Huang Z H. Ownership structure and performance of listed companies. Economic Research Journal, 1999, 12: 23-30.

[11] Chen X Y, Wang H. Check-and-balances of shareholder and corporate value: Model and empirical evidence. Quantitative and Technical Economics, 2004, 11: 102-110.

[12] Bai C E, Liu Q, Lu Z, et al. An empirical study of the governance structure of Chinese listed companies. Economic Research Journal, 2005, 2: 23-30.

[13] Liu X, Liu W. Monitoring or colluding? — Study on the relationship between shareholder structure and firm value in China's listed companies. Accounting Research, 2007, 6: 68-75.

[14] Tu G Q, Liu F. Between the nature of shareholders in power balance and the effect of power balance. Management World, 2010, 11: 132-142.

[15] Tong Y, Chen S S. Firm life-cycles, power balance and corporate value. Nankai Business Review, 2010, 1: $108-115$. 
[16] Maury B, Pajuste A. Multiple large shareholders and firm value. Journal of Banking and Finance, 2005, 29(7): 1813-1834.

[17] Gao L, He S H, Huang Z Z. Corporate governance and tunneling. China Economic Quarterly, 2006, 4: $1157-1178$.

[18] Lv H L, Li W L. Study on the relationship between controlling shareholders' self-interest behaviors and corporate balance mechanisms. Management Review, 2010, 22(3): 19-28.

[19] Zhu H J, Wang H. Can “check-and-balance of stock ownership" improve company's control? — A case study of struggle for the controlling right of Hongzhi science and technology limited company. Management World, 2004, 10: 114-123.

[20] Zhao J W, Yu Z B. Can check-and-balance ownership structure improve firms' operating performance? Accounting Research, 2005, 12: 59-64.

[21] Xu L P, Xin Y, Chen G M. Ownership concentration, outside blockholders, and operating performance: Evidence from China's listed companies. Economic Research Journal, 2006, 1: 90-99.

[22] Luo J H, Wan D F. Private benefits of control of incumbent shareholders: Theoretical model and empirical findings. Systems Engineering — Theory \& Practice, 2011, 31(2): 229-238.

[23] Wu D M, Zhuang X T. The nature of ownership, corporate governance and private benefits of control: Evidence from China's listed companies. Management Review, 2011, 7: 53-60.

[24] LI B, Sun Y J. Analysis of the relationships between ownership structure and corporate performance under the influence of stage characteristics of firm growth. Finance and Trade Economics, 2007, 6: 39-44.

[25] Li B, Liu F W, Lu W B. Governance effect research on check-and-balance of stock ownership based on the company performance volatility. Management World, 2009, 5: 145-151.

[26] Song M, Zhang J X, Li C T. A trap in the ownership structure for listed companies. Nankai Business Review, 2004, 7(1): 9-23.

[27] Cao T Q, Yang X L, Sun Y G. Ownership structure and corporate performance: Measures and endogenity. Economic Research Journal, 2007, 53(10): 126-137.

[28] Baron D P. Non-cooperative regulation of a nonlocalized externality. RAND Journal of Economics, 1985, 16: $553-567$.

[29] Wu W Q, Chen M, Wu T Y. Multi-principal multi-agent problem in tax evasion. Economic Management Journal, 2009, 458: 150-155.

[30] Long X H, Tian C Z, Duan W C. Entrusted agency: Manager behavior, accounting information assurance and investors. Economic Research Journal, 2009, 9: 140-151.

[31] Khalil F, Martimort D, Parigi B. Monitoring a common agent: Implications for financial contracting. Journal of Economic Theory, 2007, 135(1): 35-67. 